\title{
EL PRINCIPIO SOCIOANTRÓPICO: LA CONEXIÓN LIBERTAD-DETERMINISMO Y UNA NUEVA ESTRUCTURA EXPLICATIVA PARA LAS CIENCIAS SOCIALES
}

\author{
JORGE GIBERT GALASSI \\ Universidad de Viña del Mar
}

\begin{abstract}
My purpose is to postulate a principle, which I call "socioantropic", that can connect in a proper way two historically antithetical notions: free will and determinism in the social word. The main consequence of this is the establishment of a new kind of explanatory structure more in keeping with the special nature of the social sciences. To this end, I shall reconstruct the conventional structure of deductive-nomological explanations, exposing its shortcomings in relation to the social sciences, and hence I shall formulate a proposal for the theoretical resolution of the problem of explanation in the social world.
\end{abstract}

\section{Introducción}

La idea que la ciencia social y la filosofía están conectadas ha cobrado relevancia en el último tiempo (Little 1998; Bunge 1999b). Tal idea adopta nuevos bríos y nuevas formas debido a la enorme crisis de legitimidad de las ciencias sociales, que según varios autores es producto de una gama de movimientos denominados postmodernistas, relativistas o constructivistas (Sokal y Bricmont 1998; Bunge 1993).

Una de las aristas del debate sobre la legitimidad y status de la ciencia social consiste en afirmar si ella es o no una ciencia objetiva en propiedad. ${ }^{1}$ La tradición durkheimiana ha sostenido que la sociología es una ciencia social objetiva, mientras que autores contemporáneos han afirmado que es una disciplina que no permite distinciones entre hecho y representación, debido a la diferencia entre realidad natural (objetiva) y social (subjetiva). Algunos de esos argumentos serán refutados a lo largo del trabajo, pero se insistirá en que la diferencia sustancial de la ciencia social respecto a otras disciplinas estriba en el fenómeno y tratamiento de la libertad humana.

Todo tipo de teorías estructuralistas y funcionalistas han sostenido que el agente es conjuntamente constreñido y motivado por la estructura, que es mantenida o alterada por el libre albedrío de la acción individual; y sin embargo jamás se ha explicado con suficiencia cómo es esto posible.

Principia, 12(1) (2008), pp. 1-33. Published by NEL - Epistemology and Logic Research Group, Federal University of Santa Catarina (UFSC), Brazil. 
El enfoque que adoptaré en el trabajo es compatibilista, que quiere decir que por más que nuestra acción individual forme parte de cadenas causales, somos libres de romper o innovar en alguno de los eslabones de esas cadenas. Ello hace posible la responsabilidad moral y la ética.

Nuestra propuesta se fundamenta en tres observaciones radicales, interconectadas:

1. La epistemología de las ciencias sociales no ha resuelto la antinomia libertad-determinismo en el mundo social;

2. debido a que la explicación de fenómenos sociales se ha reducido básicamente a que "lo social se explica por lo social", que excluye el libre albedrío de los agentes;

3. lo que genera un déficit explicativo sustancial en las ciencias sociales. Pensamos que tal déficit es expresión de una carencia en la estructura lógica del modelo nomológico deductivo de explicación en ciencias sociales.

Así, la tesis es que las ciencias sociales exhiben un importante déficit explicativo debido a una solución errónea del problema libertad-determinismo. Rebatimos tanto el ideal voluntarista (cuyo término central es la libertad) como el ideal naturalista (cuyo término es el determinismo), que se plantean excluyéndose entre sí. Sustentamos una filosofía de las ciencias sociales "sistémica realista". Ella se fundamenta en especial en la idea de que las cosas particulares están conectadas en algún sentido o medida con el todo, luego la legalidad existe. Pero también existe la libertad, que equivale a la desconexión en alguna medida o respecto de las cosas particulares con el todo y los sistemas incluidos en él. Ello es posible porque la realidad posee una estructura ontológica de múltiples niveles. Pensamos que existe una conexión entre libertad y determinismo, tanto a nivel psicológico individual como a nivel social. Centraremos nuestra discusión en el caso social, diciendo que los actos libertarios surgen en la esfera social y ello hace posible que "la sociedad moldee a los individuos y los individuos moldeen la sociedad".

El propósito de este trabajo es postular un principio, que llamare "socioantrópico", que permita conectar en el mundo social de una manera adecuada dos términos históricamente antitéticos: libre albedrío y determinismo. La principal consecuencia al hacer esto consiste en establecer un nuevo tipo de estructura explicativa acorde a las características especiales de la naturaleza del mundo social. Para hacerlo, reconstruiré la estructura convencional de la explicación nomológica deductiva mostrando aquellos aspectos que no son útiles en ciencias sociales y posteriormente, formularé una propuesta que resuelve teoréticamente el problema de las explicaciones en el mundo social.

Principia, 12(1) (2008), pp. 1-33. 


\section{La conciliación de los términos del debate}

La teoría social está cruzada por soluciones o bien deterministas o bien libertaristas (voluntaristas), que responden parcialmente a la fenomenología de lo social. Marx intento conectar ambas tesis — "los hombres hacen su propia historia, pero no la hacen a su libre arbitrio ... sino bajo aquellas circunstancias con que se encuentran directamente ..." (Marx 1971, p. 11) — y la teoría sociológica contemporánea lo ha traducido bajo la fórmula misteriosa de "la sociedad moldea a los individuos y los individuos moldean a la sociedad" (sin describir el "cómo"). Acá las entidades son "sociedad" e "individuo", lo que plantea las siguientes alternativas para la relación entre sociedad e individuo. Desde el punto de vista ontológico, se afirma que ambas entidades existen, pero en el caso de la "sociedad", la duda se ha planteado si existe como agregación o como totalidad. La noción de individuo plantea la presuposición que hablamos de agentes intencionales, sin olvidar que cabe la posibilidad que tales agentes sean víctimas de algún orden superior en su conducta, como insiste el holista o colectivista. Desde un punto de vista causal, la pregunta es si la sociedad origina a los individuos o bien si los individuos producen a la sociedad. Habitualmente, los atomistas han insistido en lo segundo y han sustentado algún modo de voluntarismo, mientras que las ciencias sociales siempre han sido no atomistas, a saber, han presupuesto que el individuo depende de las relaciones sociales para que aparezcan en él todas sus capacidades distintivas como ser humano.

Si el individuo posee la cualidad del libre albedrío y la sociedad el atributo de coaccionar o constreñir; si suponemos que tal conexión entre sociedad e individuo existe, entonces, el problema es el cómo. Lo que plantearemos es que existen una amplia gama de entidades intermedias que conectan la sociedad con los individuos, muchas de ellas implicadas o portadoras de mecanismos que explican esa conexión. Básicamente, estas entidades intermedias son distintos tipos de sistemas productores de la dinámica social.

La ciencia social se ocupa de procesos interactivos y de agregación cuyos elementos son los agentes intencionales. Ahora bien, si la disciplina posee pretensión científica, esto es, de postular un transmundo estable de leyes, de relaciones regulares, entonces debe integrar la libertad de los agentes como un hecho, constitutivo o emergente de un sistema. Luego, debería estar regulada su existencia o emergencia. En otras palabras, si es un rasgo o propiedad sistemática de la condición humana, debe expresarse regularmente o, al menos, deberían estar reguladas las condiciones de su aparición. Es lo que intentamos dilucidar.

Principia, 12(1) (2008), pp. 1-33. 


\section{Libre albedrío y mundo social}

La libertad individual originaria, el porqué un hombre actúa moralmente de manera inusitada, contra sus patrones conductuales e incluso contra su integridad física, continuará siendo objeto de meditación metafísica. Sin embargo, pensamos que podemos centrar una discusión sobre el fenómeno de la libertad desde la filosofía de las ciencias sociales.

Partiré afirmando que la libertad como fenómeno es imposible sin determinismo. En el mundo físico, la opción de volar no tiene sentido pues hay gravedad. En un mundo donde las cosas simplemente se suspendieran por los aires, volar no sería opción sino la única posibilidad. En el mundo social hay opciones. Empíricamente, entonces, la libertad es realizar un curso de acción que se ha elegido entre varias alternativas. ${ }^{2}$

La existencia de determinismos permite que ciertos eventos humanos puedan ser calificados como libres ya que precisamente su característica consiste en quebrar o innovar en las cadenas causales vigentes o crear nuevas cadenas causales. Ya que sabemos "cómo son las cosas" (como están determinadas las cosas), podemos elegir, escoger entre alternativas que se desprenden de la fisonomía de lo que la realidad es, transformándola. Así, el hombre construye un mundo artificial permanentemente mediante el uso de su libertad en la historia.

Paradojalmente, la libertad humana es producto de un determinismo biológico, que consiste en la plasticidad neuronal y una capacidad de reconexión neuronal espontánea, que quiere decir que se nos ocurren cosas -ideas y arquitecturas- aún sin el concurso del condicionamiento del medio ${ }^{3}$. La libertad es vista como una consecuencia de una capacidad instalada en el sistema nervioso central. La ocurrencia es la madre de la cultura y la cultura es el marco donde actualizamos nuevas ocurrencias. Ontológicamente, a nivel individual, somos libres debido a razones neurofisiológicas (reconexión neuronal espontánea), mentales (relaciones originales entre cosas, eventos y otras ideas) y conductuales (libertad de hacer). Las palabras claves son "creación"-"innovación”-"quiebre”. Creación de objetos, creación de reglas (éticas o morales), creación de conducta (aún cuando prácticamente todas las conductas son innovaciones de conductas típicas de primates superiores). Innovación, cambio de ideas antiguas por otras ideas nuevas; reemplazo de conductas afuncionales por otras, innovación en la fisonomía de los productos del mundo material (más efectivos). Finalmente, quiebre: de objetos que no se recrean, respecto de ideas (que se olvidan) y respecto de conductas, que se censuran y cambian. Es, simplemente, voluntad puesta en acción en el mundo. La libertad entendida como creación-innovación-quiebre, se

Principia, 12(1) (2008), pp. 1-33. 
origina en el nivel individual, e impacta al entorno social. Obviamente, nuestro empeño es rescatar un papel en la estructura lógica de la explicación sociológica para el individuo y en ningún caso plantear la fantasía que la sociedad podría alguna vez verse determinada por una acción individual.

La libertad es una creación tardía de la historia y consiste, en rigor, en el cambio de las situaciones precedentes mediante acciones intencionales. La libertad implica tiempo, novedad y pertenencia sistémica. Tiempo, pues la novedad se "gesta y desarrolla" en la mente individual y toma tiempo que "los otros" la acepten como tal, como innovación legítima capaz de encadenarse causalmente con sistemas determinísticos. Novedad es lo "que vendrá". Desde el momento que algo es reconocible pierde novedad. Luego, la libertad es lo factible, lo posible, entre las alternativas existentes teóricamente. En un sistema fáctico, la novedad se forja como ruido y no es posible en un primer momento determinar conceptualmente de que se trata eso "novedoso" y ontológicamente la entidad o propiedad nueva tampoco ha cristalizado como algo ya dado, como efecto al interior de un sistema. La pertenencia sistémica de la libertad significa algo tan lacónico como que toda acción intencional emerge en una situación dada que se inscribe en algún sistema social operante.

Finalmente, la libertad siempre se encuentra en un presente conectado a un futuro. Somos libres de decidir, pero al hacerlo, dejamos de ser libres ya que nuestra decisión nos ató a sus consecuencias prácticas. y así sucesivamente. Es decir, la libertad existe, pero es efímera y debemos actualizarla permanentemente. Esto da esperanzas respecto a la posibilidad de direccionar las sociedades humanas, aunque tales modalidades sean inciertas.

\section{Determinismo y mundo social}

Un comienzo podría ser reconocer que existen dos clases de pautas en el mundo social: las naturales (regularidades legaliformes) y las construidas (regularidades regladas). Las primeras son más determinísticas y las segundas no, dependen del libre albedrío en sistemas determinísticos. Sin embargo, muchas regularidades se refieren a las modalidades de la convivencia social fuertemente determinadas por reglas que "generan leyes". Es decir, mientras existen reglas creadas de convivencia, éstas generan leyes pues es inherente al funcionamiento de tales reglas que se manifiesten ciertas leyes para que ello ocurra (Bunge 1999b, p. 141).

Así, el alcance y status de las leyes sociales varían bastante. Por un lado, tenemos las leyes "naturales" de lo social (como que los gobiernos siempre quieren 
más poder; o la ley que los mercados libres generan desigualdades) y por otro lado las leyes construidas o reglas, menos estables y de algún modo intercambiables, como las del juego político (que varían si el régimen es parlamentario o totalitario). A estas últimas deberíamos trabajarlas como leyes no universales emergentes. En otras palabras, las leyes estables operan y son el océano social, mientras las reglas que pretenden imponer ciertos grupos o elites son olas que modifican la quietud del océano llamado historia. Pero no es un problema de gradualidad, sino ontológico: dos tipos de condicionamiento sociales diferentes. Con esto, refutamos la idea de las "sumatorias de buenas voluntades individuales", las que todas juntas y al unísono, generan los grandes cambios históricos.

Ahora bien, toda regularidad en el mundo social debería implicar mecanismos. Nuestra visión es que un mecanismo social es un proceso en un sistema que involucra al menos dos agentes encargados de crear, mantener, transformar o desmantelar un sistema social. Todo mecanismo social, aunque constreñido por las leyes naturales y sociales creadas, son conducidos por acciones que siguen reglas convencionales que pueden modificarse. Hay causalidad y legalidad. Lo que faltaría agregar es que las regularidades operan en sistemas en la realidad social, donde los hombres - con su libre albedrío- permanentemente contribuyen a la variabilidad de tales sistemas. ¿Porqué la economía es incapaz de predecir recesiones? Una respuesta es que los agentes económicos han asumido su libertad y su capacidad de operación en los eslabones de las cadenas causales de la dinámica económica (como la política fiscal o monetaria) con lo que han logrado retardar las recesiones o bien hacer imposible su surgimiento. La economía y demás ciencias sociales yerran al utilizar en sus pronósticos de largo plazo esquemas filosóficos naturalistas. Naturalmente, muchos pronósticos de corto plazo funcionan bien, pero debido a la estabilidad del juego de expectativas.

En el centro de esta discusión, nos encontramos con el concepto de ley.

Se sigue dudando, en general, de la realidad de las leyes postuladas por las teorías de todas las disciplinas, incluidas la física. Esa doctrina se llama antirrealista teórica (Dutra 2003, p. 30). Nuestra postura es que los requisitos exigidos son excesivos. Si imponemos todas las restricciones, acabaríamos por pensar, simplemente, que no existen las leyes, pues todas son, strictu sensu, hipótesis con algún grado de confirmación. Sin embargo, como plantea Nagel, incluso "el escepticismo radical tiene que confiar en algunos pensamientos que no son puestos en duda y cuyo contenido objetivo se asume. Pero lo mismo debe suceder con formas menos radicales de incertidumbre, con la confianza ordinaria, limitada, que tenemos en la mayoría de las propias creencias, incluyendo la creencia condicionada en las teorías científicas que son aceptadas, por el momento, como las

Principia, 12(1) (2008), pp. 1-33. 
mejores, aun cuando sabemos que serán superadas. El razonamiento que sustenta tales creencias debe ser en algún nivel también incondicional, porque si no, no podría mostrarnos lo que podría ser objetivamente cierto" (Nagel 2000, p. 94-5). Entonces, las leyes científicas no afirman conjunciones de hechos, sino relaciones entre rasgos seleccionados; y tampoco afirman la igualdad de los individuos, sino la invariancia de ciertas relaciones, independientemente de los cambios que pueda haber en los valores de las variables individuales. En particular, un enunciado legaliforme que suponga tiempo no tiene por que ser una ley de recurrencia: los esquemas recurrentes no son más que una subclase propia de los esquemas en general. Todo lo que afirma una ley científica es que hay diferencias individuales que cumplen en ciertos respectos ciertos esquemas o ciertas estructuras. Dicho brevemente: una ley es un esquema de variedad y cambio (Bunge 1983, p. 342).

En los manuales de ciencias sociales, son escasas (o nulas!) las referencias a leyes de la sociedad, salvo las jurídicas. La única excepción es la economía (ley de oferta y demanda; curva de Phillips; etc.). Sin embargo, existen proposiciones que —al menos_ suponen regularidad (o legalidad). Algunos ejemplos son: (i) La ley de hierro de la oligarquía, "el poder se transfiere familísticamente", de Michels (1962); (ii) La ley de Parkinson (1957), "el trabajo se extiende para ocupar el tiempo y el personal disponible"; y, (iii) Los 5 dilemas de O’Dea (1966), especies de ecuaciones simples donde se ilustra que en la historia de las religiones, siempre hay un equilibrio inestable entre dos factores en 5 dimensiones.

Independientemente de si en rigor estas proposiciones son leyes teóricas o empíricas, leyes o hipótesis, recogen ciertas regularidades bastante universales.

Curiosamente, el argumento en contra de un modelo de cobertura legal es la inexistencia de leyes generales en la sociedad. La predicción es posible dentro de un sistema cerrado y precisamente las intenciones humanas, que afectan los sistemas cerrados, hacen imposible tanto las leyes, como las explicaciones y predicciones. Pero ello desatiende el hecho que es posible pensar en explicaciones inter niveles no-reductivas.

Bunge (1983) expresa similares distinciones y plantea que es un error pensar que existen leyes universales de algún tipo. Habría que agregar que, por ejemplo, en el caso de la biología, todas las leyes descubiertas rigen en el ámbito de la biosfera, pues no sabemos cómo éstas se desempeñarían fuera de ella.

Para los fines de esta exposición, se trabajará con una concepción de legalidad débil, que es la siguiente: ley es un enunciado hipotético que ha sido confirmado empíricamente respecto de una relación aproximadamente constante o probable, bajo ciertos parámetros, entre dos o más variables. Por lo demás, la misma tradición de las ciencias sociales, desde Pareto y su célebre ley de distribución de las

Principia, 12(1) (2008), pp. 1-33. 
rentas, sostiene esta definición. Obviamente, esta es una definición débil, pero se corresponde con el estadio de desarrollo de las ciencias sociales.

Por ejemplo, "el sociólogo histórico Michael Mann propone muchas generalizaciones, la mayoría características de una región y un período dados. Éstas le sugieren que, lejos de ser caótica, la sociedad humana es "un desorden pautado", vale decir una combinación de ley y accidente: exactamente lo que habíamos sospechado de su análogo, la evolución biológica” (Bunge 1999a, p. 38). Sólo las leyes sociales teóricas son "universales", pero a costa de un conjunto no siempre despreciable de supuestos.

Las leyes sociales son expresiones de transferencias fuertes de poder, dinero, prestigio (todo lo "social" posee una magnitud — sin importar el criterio o metodología de medición) y señales (transferencias débiles), tales como decretos, "comunicados"; "declaraciones" (los trascendidos de prensa, que reflejan habitualmente opiniones institucionales, son de gran importancia).

Lo cierto es que disponemos o podemos deducir leyes deterministas en lo social. Pero es muy difícil encontrar leyes sin excepciones. Habitualmente encontraremos excepciones del tipo "siempre que $B$, se da $C$, a menos que $x$ ". En la práctica, seguramente la expresión empírica de una ley será "se da $A$ cuando, $B$, siempre que $u, v, w, x, y, z)$. Pero un caso como el precedente es de escasa utilidad como ley. Es, utilizando el sarcasmo, una "ley etnográfica". Pero, el que la mayor parte de las leyes sociales sean restringidas o estocásticas no las invalida (Gibson 1968).

\section{Nuestro principio socioantrópico}

Una noción central de nuestro planteamiento es "sistema social". Así, comenzaremos por explicitar nuestro concepto de sistema (Bunge 1997, p. 180-1).

Definición 1. La terna ordenada $n=\langle\mathrm{C}(s), \mathrm{M}(s), E(s)\rangle$ representa un sistema concreto s sí y sólo si

$\mathrm{C}(\mathrm{s})$, llamada la composición de $s$, es el conjunto de los elementos de $s$; $M(s)$, llamado el medio de $s$, es el conjunto de los elementos, diferentes de los elementos de $s$, que se relacionan y vinculan con éstos; y

$E(s)$, llamada la estructura de $s$, es el conjunto de las relaciones y vínculos entre elementos de $s$, o elementos de $s$ y elementos del medio de $s$.

Definición 2. Sea P una propiedad de bulto de un sistema s (o sea, una propiedad de s como un todo). Entonces

Principia, 12(1) (2008), pp. 1-33. 
$P$ es una propiedad resultante de $s$ si y sólo si $P$ es también poseída por alguno de los elementos de $s$; de lo contrario, $P$ es una propiedad emergente (o gestalt) de $s$.

Un enfoque que conecta las tesis de la libertad con las del determinismo puede ser auspicioso, en virtud del hecho que ha decrecido la fracción de sistemas sociales espontáneos con respecto a los planificados (burocracia, salud pública). En general los sistemas espontáneos (mercados, pandillas) sólo podemos comprenderlos ex-post y la modelación y predicción es en la práctica imposible. Podemos comprenderlos, pero muy parcialmente, en especial en los sistemas pequeños, donde siempre se deben esperar grandes fluctuaciones. En cambio, en los sistemas planificados o diseñados, aunque evolucionan de forma a veces imprevista, en general pueden ser comprendidos y explicados, cuando no predichos. Podemos conocerlos, ya que tales sistemas poseen determinados tipos de organización.

Así, un sistema es un conjunto de componentes, estructura y relación con el medio. Los componentes sistémicos tienen una función específica y el cómo están interconectados constituyen sus mecanismos específicos. Siempre los mecanismos deben ser conjeturados a partir de la información empírica y consistentemente con ella.

Un mecanismo es la forma que proceden ciertas reglas o procedimientos y es algo real. Los mecanismos pueden ser objetivos y subjetivos: "motivos-porque" y "motivos-para" (Schütz \& Luckmann 1973). Un determinado mecanismo puede ser modelado de diferentes maneras y muchos mecanismos hipotéticos (la mano invisible por ejemplo) no tienen referencia fáctica. La estructura de un mecanismo es una propiedad, no una cosa. Además, todo mecanismo es tanto para cambiar como para controlar el cambio. Finalmente, Todo mecanismo es un proceso, pero no todo proceso es un mecanismo.

En términos causales, se deben distinguir dos tipos de mecanismos causal:

1. Transferencia de energía: transferencia fuerte de energía (por ejemplo, las acciones sociales visibles); y,

2. Transferencia débil de energía: señales (dar indicaciones, órdenes, comunicación y sentido). Sistemas inestables pueden ser quebrados por una sola persona. Esa es la razón por la cual los sistemas sociales están dotados con sistemas de comunicación.

La mejor forma de trabajar los mecanismos es a través de leyes dinámicas, en vez de leyes kinemáticas. Estas últimas, sólo nos informan de que $\langle a$ impli- 
ca $b\rangle$. Por el contrario, la ley dinámica explicita mediante afirmaciones del tipo $\langle a$ implica $m\rangle,\langle m$ implica $b\rangle$. Si reemplazo $m$ por $n$, fenomenológicamente el resultado sigue siendo $a$ implica $b$. Para el positivista, esto demuestra que los mecanismos son dispensables. Para el realista, en cambio, que las hipótesis mecanísmicas son más ricas que las de caja negra, pero deben comprobarse.

Por ello, y no por dogma, es que las ciencias sociales científicas requiere aplicaciones específicas, al igual que las ciencias naturales.

Hagamos el siguiente experimento teórico: el desarrollo de un bosque esta determinada por las leyes generales de un sistema o dominio, la biosfera en este caso. Pero ese mismo bosque, particulariza su desarrollo dependiendo de factores como clima, suelo, etc. Ello es exactamente lo mismo que las sociedades humanas. Ellas particularizan su fisonomía de acuerdo a leyes generales, como por ejemplo, las sociedades son autocorrectivas en cuanto a lo institucional, es decir, no permiten la entropía total, aún cuando se desempeñen de diverso modo a lo largo de la historia (como imperio o nación) o se fragmenten, para impedir la entropía, como la ex-unión soviética. En suma, la estructura de legalidad es idéntica, pero las circunstancias permiten que los explanandum sean distintos.

Ahora bien, psicológicamente, la variabilidad es más alta y, como "alguien" será primer ministro, líder religioso o todo el resto de posiciones sociales de alto impacto, entonces, esa sociedad recibirá el impacto del desempeño social de ese individuo y su psicología particular. Pero este impacto no es directo, está configurado psicosocialmente, que es lo que opera como factor directo en última instancia. Luego, toda legalidad social, más específicamente considerada, debe considerar el nivel inferior, que no es el biopsicológico sino el psicosocial, ello porque las decisiones y los estilos de hacer las cosas son "lideradas" por líderes individuales pero sufren modificaciones de fondo y forma en el proceso decisional o de implementación. Es decir, mezclando el nivel social con el nivel psicosocial y —obviamente- mezclando también dentro de lo social las esferas culturales, económicas y políticas.

Cuatro enunciados pueden ayudarnos a seguir el argumento:

1. los sistemas sociales están constituidos por múltiples niveles de realidad;

2. cada nivel de realidad tiene una operatoria o una legalidad artificial bastante estable;

3. tales operatorias son disímiles pero se vinculan entre sí, también de manera estable; $y$,

4. el nivel básico de toda ontología social son las expectativas presentes y de futuro entre individuos libres.

Principia, 12(1) (2008), pp. 1-33. 
La regularidad de un fenómeno social se explica debido a que las expectativas entre individuos libres de un sistema son estables, luego el sistema es predecible en el corto plazo. Por el contrario, la variabilidad de un fenómeno social no es imputable al hecho que no exista determinismo en un sistema social, sino a que las expectativas de los agentes al interior de los sistemas son inestables y esa inestabilidad repercute en los otros niveles, puesto que hay mecanismos que los conectan.

A nivel individual, la variabilidad de la conducta puede ser asociada a un mecanismo causal interno, la voluntad, y la libertad de llevar a cabo la voluntad.

Nuestro principio de análisis sistémico lo denominaremos "socioantrópico", para enfatizar la tesis no atomista de la filosofía social que el individuo depende de las relaciones sociales para que aparezcan en él todas sus capacidades distintivas como ser humano y, además, para enfatizar que el análisis de la conducta individual está incompleto (o simplemente errado) sin el estudio de la historia y la dinámica de los sistemas sociales en que tal conducta ha estado inserta. Pero lo realmente original consistiría en el reemplazo de la tesis fundacional de Durkheim, dando paso a la idea que la historia y la dinámica de los sistemas sociales otorgan un rol relevante a los individuos 'destacados', esto es, a los organizadores e innovadores. Así, lo social no se explicaría solamente por lo social, sino por nuestro principio socioantrópico, que conectaría la libertad individual con el determinismo social.

Este principio, indicaría lo siguiente:

El determinismo social opera de manera más intensiva y menos extensa en la cúspide de lo social; mientras que opera menos intensivamente pero más extensamente en la base, los sistemas de interacción. En el borde, el individuo puede ser visto como una maquina determinada biológicamente y como un ser síquico libre "de pensar lo que quiera". En el primer nivel social, la más simple interacción, determinismo y libertad actúan al unísono y en un grado de influencia similar. Ello es así porque la interacción social consiste en la orientación intencional mutua entre dos agentes $(\alpha$ y $\beta)$. Sin la aceptación de esto, es decir, de libremente dejarse determinar por algo en común (el código del amor en el caso de un galanteo, el beneficio mutuo en un intercambio económico) no hay interacción social (pero puede haber imposición y esclavitud). Sin embargo, todo sistema interactivo al definir referencias sistémicas mayores, por ejemplo, organizacionales o del nivel grupal, abre dos situaciones: a) optan $(\alpha$ y $\beta)$ a la determinación de ciertas reglas grupales (por ejemplo a acatar cierta norma) o, b) a ejercer su libertad como sistema interactivo que opta por desacatar dichas determinaciones (por ejemplo, que el interés monetario gobierne una relación amorosa).

Principia, 12(1) (2008), pp. 1-33. 
Lo anterior funciona horizontal y verticalmente. Horizontalmente, la libertad funciona como coevolución con sistemas de un mismo nivel (entre países, al firmar un tratado comercial, por ejemplo); mientras que verticalmente, la libertad de un sistema funciona como entorno del determinismo de un sistema superior (cuando una organización quiebra mediante la innovación con la práctica dominante de la economía, por ejemplo, sin que ello signifique que cambie la economía), así como también cuando un sistema libremente impone por su dinámica un nuevo determinismo hacia en los niveles inferiores (cuando una organización redefine los estándares de desempeño en los equipos de trabajo que la constituyen, lo cual significa que cambia la dinámica de ese sistema inferior, por ejemplo, existe menos tiempo para "compartir" entre los empleados).

Los individuos poseen mayor libertad mientras más grande sea el agregado que los cobija como miembros. Pero, para ser cobijados en ese agregado, deben resolver la coordinación acatando reglas determinísticas (que mientras más grande es el agregado más simples son, por ejemplo, el intercambio económico en el sistema económico), lo que permite hacer funcionar la coordinación del agregado. Pero la libertad individual se restringe mientras más pequeño sea el agregado que los cobija, pues pueden resolver la coordinación con menos reglas fijas, pero más determinados por las expectativas mutuas, más complejas, como en la interacción social.

La determinación es más fuerte en los agregados a medida que estos son mayores, pues las reglas deben ser más simples, pero por lo mismo más rígidas. Ello no significa que la libertad individual sea menor, en tanto elemento de ese sistema mayor. Pero la propiedad emergente implica que el agregado de individualidades se rige por tales reglas emergentes de manera determinística. La coordinación social (diferenciación e integración) se realiza mediante reglas. Las reglas condensan en determinado nivel, las características que adoptan la libertad y el determinismo social. La libertad no existe en abstracto. Siempre es función del tipo de elemento incorporado en un cierto nivel de la estructura social.

La libertad individual en el nivel grupal es función de la aceptación o rechazo de las reglas imperantes en un sistema de ese nivel. Puede ser libre en toda conducta menos en aquellas asociadas a tales reglas. Nunca somos libres de modo absoluto en sociedad, pero la contraparte es que nunca estamos determinados absolutamente en sociedad, pues en un intercambio económico tenemos libertad de escoger el lugar y el tiempo, el lenguaje y gestos de nuestra interacción y muchos detalles más, a excepción del hecho que, finalmente, "pagaremos y recibiremos algo a cambio": eso está determinado.

No se puede exportar la libertad de un nivel inferior a un nivel superior de

Principia, 12(1) (2008), pp. 1-33. 
la estructura social. Sólo se puede condicionar, preparar el terreno, generar precedentes para situaciones futuras. La presión desde arriba siempre es grande. Por eso, sólo pueden romperla los "grandes líderes", pero nunca voluntarísticamente.

Podemos conceptualizar los niveles de la estructura social total siempre de varias formas. Una primera forma es en términos restrictivos, enfatizando sólo las características identitarias. Así, en el nivel superior máximo, sistemas instrumentales (economía, derecho, político, etc.), las características serían aquellas reglas determinísticas de funcionamiento exclusivo donde la doble contingencia se define como las expectativas recíprocas respecto a una operación que permite la reproducción del sistema en cuanto sistema (el intercambio en el caso de la economía, el dictamen en el caso del derecho, el uso del poder en la política). Lo mismo con los otros niveles.

Otra forma, sería al interior de cada nivel, conectando cada subsistema de un cierto nivel con otros subsistemas de ese mismo nivel. Por ejemplo, todos los subsistemas del nivel superior, viendo las operaciones que permiten la coevolución de las reglas determinísticas que conectan a dos subsistemas (el contrato, para el caso de la conexión derecho y economía; los proyectos de ley, para el caso de la conexión derecho y política; la política fiscal y monetaria para el caso de la conexión economía y política, etc.).

Finalmente, la forma más compleja sería conceptualizando las relaciones hacia arriba y hacia abajo entre los distintos niveles y las relaciones horizontales entre subsistemas de cada nivel. Es en este esquema donde aparece la libertad, como: (i) creación-innovación-quiebre de las reglas de un cierto sistema de cierto nivel, producto de la difusión de la creación-innovación-quiebre de las reglas de un sistema inferior hacia arriba; y, (ii) creación-innovación-quiebre de las reglas de un sistema inferior debido a la imposición de la creación-innovaciónquiebre de las reglas del sistema superior.

Las consecuencias claves de lo anterior son que: (i) un sistema inferior no puede imponer reglas hacia arriba (no existen los recursos para ello) y (ii) un sistema superior no puede difundir seducir hacia abajo nuevas reglas (no existe el tiempo para ello).

Ahora bien, desde la distinción elemento-agregado (estructura que emerge de las relaciones entre los elementos), podemos hacer algunas afirmaciones:

1. Mientras mayor sea el número de elementos (unidades sociales) de un nivel, mayor libertad tendrán tales elementos en el dominio del agregado (pues es imposible que generen vínculos significativos con todos y las posibilidades de romper relaciones y reemplazarlas son más probables) y; a

Principia, 12(1) (2008), pp. 1-33. 
menor número de elementos en un nivel, menor libertad de los elementos en el dominio del agregado.

2. Mientras mayor sea el número de elementos más difícil es la coordinación "en todos los respectos" y más fácil la coordinación estricta en "un solo respecto determinístico" a nivel agregado; y, mientras menor sea el número de elementos más fácil es la coordinación en todos los respectos y más difícil es la coordinación estricta a base de reglas inviolables (la cercanía, la familiaridad y los aspectos idiosincráticos permiten el reemplazo de reglas y las consideraciones de excepción) en el nivel agregado.

Podemos conceptualizar a la sociedad como una estructura compuesta de cinco niveles con reglas propias: interactivo (dos individuos); grupal (tres o más: la importancia del número es la configuración del poder, donde existe un tercero que puede eventualmente romper "empates" adhiriendo a la posición de uno de los dos restantes miembros del grupo); organizacional (normas); ecológico organizacional (industrias sociales) y macrofuncional (instituciones). En cada uno de estos niveles, la ecuación libertad-determinismo se comporta de acuerdo con las afirmaciones hechas anteriormente.

\section{Las consecuencias epistémicas para la teoría social}

La primera consecuencia que se desprende de lo anterior es que solución libertaria es errónea porqué los determinismos hacen muy difícil materializar cualquier idea, por muy buena que sea, como la idea de justicia. Desde siempre hemos querido establecer el paraíso en la tierra y los esfuerzos siempre han sido en vano, independientemente de las voluntades.

La segunda es que la solución naturalista esta incompleta, ya que los hechos sociales están gobernados por ciertas leyes, pero no sometidos a ellas, como sucede con los fenómenos naturales. La regularidad de los fenómenos del mundo físico no admiten excepciones, pero las del mundo social expresan novedad permanentemente. Ilustremos con la ley de Michels "el poder siempre se concentra en unas pocas personas": adquiere realidad histórica bajo formas de concentración del poder muy diferentes, como la aristocracia y la democracia.

Una tercera consecuencia es que debemos enfatizar aún más las realidades emergentes, pues precisamente ahí se fragua la conexión libertad-determinismo, además de que en tales ejercicios, se supera en la práctica la distinción metodológica entre el individualismo y el holismo. Recientemente, este enfoque se ha robustecido (Bunge 2004).

Principia, 12(1) (2008), pp. 1-33. 
Así, desde un punto de vista epistemológico, la única forma de concebir la libertad al interior de la estructura explicativa de lo social es como de interacción accidental (las más de las veces) y deliberada (el resto), entre diversos niveles ontológicos, cuales son, el nivel neurofisiológico, el nivel psicosocial y el nivel sociocultural.

Sin embargo, la relación entre la legalidad de la naturaleza social y la de las reglas puede ser muy distinta según el tipo de sociedad. Es decir, cuanto más autoritaria sea una sociedad, menor será el impacto del uso de la libertad individual (reglas), pues está restringida, y por tanto, la variabilidad de las pautas de convivencia será menor: es una sociedad más estable. En otras palabras, la libertad individual y su grado condicionan la legalidad social y a la inversa. Pero "las personas tampoco son agentes pasivos: reaccionan sobre las redes mismas en las cuales se encuentran incluidas" (Bunge 2004, p. 125).

\section{El enfoque nomológico}

Una definición de explicación desde el enfoque nomológico es que: "Toda explicación racional de un hecho es una secuencia hipotético-deductiva que contiene generalización (es) e información. Si la generalización (s) y la información son científicas y la argumentación es correcta (lógicamente válida), hablamos de explicación científica, y también de explicación nomológica, con objeto de subrayar el papel de la ley científica en ella, o de explicación teorética, para aludir a la situación de la argumentación en un cuerpo de teoría" (Bunge 1983, p. 567).

Explicar científicamente un hecho $X$ equivale a responder a la pregunta acerca de "porqué se produce $\chi$ ", y las respuestas adecuadas a esta clase de interrogantes no puede dejar de incluir la mención de leyes generales. Desde una perspectiva lógica deductiva, la explicación es la transferencia de la verdad de las premisas a las conclusiones.

Pero: ¿Cómo damos cuenta de las regularidades?

La explicación científica convencional deriva del modelo propuesto por Newton, canon habitualmente denominado nomológico deductivo (Hempel 1988, p. 247-53) dado que las leyes de Newton, sobre todo la segunda, no solo explican científicamente diversos hechos físicos (movimientos de planetas, mareas, etc.), sino que también dan razón de leyes previamente aceptadas, como las de Galileo. La concepción hipotético-deductiva de la ciencia siempre ha tenido en cuenta que la explicación científica no solo se refiere a hechos, sino también a enunciados generales previamente confirmados por la experiencia, y se caracteriza por la 
tesis de la simetría entre explicación y predicción. Toda explicación científica es potencialmente una predicción razonada, basada en leyes. Lo anterior puede ser resumido de la siguiente manera:

- Condiciones iniciales (asociadas a un hecho) + leyes ó teorías (relativas a la ocurrencia del hecho) = explicación del hecho.

- En el lenguaje técnico, las condiciones y teorías (o leyes) pueden ser varias, y se denominan explanans, mientras que el hecho constituye el explanandum. Las condiciones y teorías implican lógicamente el hecho.

Sin embargo, el mismo Hempel (1988, p. 247-53), previene respecto a que no todas las explicaciones cumplen con este requisito. Muchas veces puede explicarse un hecho mostrando que su ocurrencia resulta estadísticamente probable a partir de ciertas leyes. Ello implica reconocer que hay un segundo modelo básico dentro del de cobertura legal, el inductivo-estadístico. La explicación estadística trata en sustancia de una explicación de una regularidad propia de un determinado nivel como resultado del juego de azar de un gran número de entidades de un nivel inferior. La explicación estadística requiere el supuesto del azar (que resulta de la independencia o cuasi-independencia recíproca de los componentes individuales) y el conocimiento de las leyes no estadísticas que se refieren a los componentes individuales. Dicho de otro modo: la explicación estadística consiste en la derivación de leyes colectivas a partir de las leyes individuales que rigen el comportamiento de los miembros de un agregado estadístico (Bunge 1983, p. 594).

El modelo nomológico ha influenciado también a la historia, habitualmente considerada una ciencia del espíritu o idiográfica. Topolski propone una metodología objetiva de la historia (Topolski 1985, p. 42), y respecto al modelo de cobertura legal de Hempel, lo acepta, pero agrega "hay que admitir que, en la práctica, nos encontramos más bien con esbozos de explicación, con referencias latentes a las leyes, aunque también se pueden encontrar casos de explicación clásica" (p. 433). Al igual que Stinchcombe (1970), Topolski enumera y desarrolla diversos tipos de explicación (causales, por referencia a disposiciones, por indicación de condiciones necesarias o suficientes y otras), e incluye entre los factores más relevantes la individualidad (y por ende la psicología individual) de ciertos actores, los líderes.

Aludiendo al objeto de las explicaciones, se postula que las explicaciones sobre acciones son las peculiares de las ciencias sociales y humanas, por cuanto en ellas interviene la libertad humana. En ellas, por tanto, el carácter mecánico 
de las explicaciones puras resulta alterado o modificado por la imprevisibilidad propia de la libertad humana.

Ahora bien, respecto a las modalidades en que esto es posible, hay discrepancias. Con todo, pareciera ser que el debate y la práctica ha fortalecido la propuesta conocida como el modelo de cobertura legal de Hempel-Nagel (Bunge 1999b).

\section{La modificación de la concepción explicativa nomológica}

En la historia de la ciencia, vemos que responder interrogantes fue primero un ejercicio de generación de falacias de antropomorfismo, y terminaron en la época moderna con la ciencia post-Galileo y el fisicalismo. Desde tal óptica, se reemplazó la motivación o pregunta "porqué" por la pregunta "cómo ocurrió eso". Sin embargo el "cómo ocurrió eso" se tradujo en una operación de subsunción de particularidades bajo generalidades. Las explicaciones eran reducciones. La modificación surge cuando se enfatiza que el rasgo más notorio de un fenómeno es su mecanismo de existencia, que - por supuesto - se conecta con leyes. El mismo Bunge parece haber adoptado tal énfasis y, oponiéndose al modelo de Hempel - que es una operación de subsunción reductiva-, postula que las explicaciones sólo pueden ser mecanísmicas.

Sin embargo, ies tal reemplazo viable o suficiente en los estudios sociales?

Pareciera que no, pues a una fenomenología física o biológica (de las que daba cuenta la óptica subsuncionista), las ciencias sociales han tratado de oponer una fenomenología genuinamente social, mediante el argumento intencional o motivacional. Ello generó la distinción entre ciencias del espíritu y ciencias de la naturaleza, entre los enfoques ideográficos y nomológicos. Desafortunadamente, no fue fructífero.

Sostenemos que antinomia comprensión-explicación es falsa y se fundamento durante el siglo XX en la confusión respecto a que la comprensión es una categoría psicológica y no epistemológica. Desde el punto de vista del conocimiento social, y del conocimiento en general, entendemos algo cuando somos capaces de explicar, es decir, de postular algún mecanismo de funcionamiento de una realidad. Es decir: (i) Mecanismo es una categoría ontológica; (ii) Explicación es una categoría epistemológica; y, (iii) Comprensión es una categoría psicológica.

Pero siendo las categorías psicológicas parte de la realidad social, debemos inferir que la comprensión constituye una parte de toda explicación social. Es decir, la comprensión que tenemos respecto de los eventos, procesos y sistemas, son una clase particular de hechos, cuya materialidad sólo podemos inferir (pues ocurre

Principia, 12(1) (2008), pp. 1-33. 
en el cerebro, como proceso mental), pero cuyas consecuencias son reales. La libertad es un hecho porque creemos en ella, y tal creencia genera consecuencias reales, como indica el Teorema de Thomas (Thomas 1928, p. 571-2). Hay dos tipos de creencias: (i) creencias con evidencia a favor o fundadas, que pueden inspirar acciones racionales y (ii) creencias sin evidencia a favor o evidencias en contra (las propiamente psicológicas o socialmente causadas), que pueden inspirar acción social a-racional o irracional. Habitualmente, la sociología "positiva" ha presupuesto la intencionalidad; mientras que la sociología "comprensiva" ha focalizado su atención exclusivamente en ella, olvidándose de las conductas reales, con los cuales está conectada pero que en ningún caso constituyen "duplicados" de ellas. La acción social es sentido subjetivo, como postuló Weber, pero podemos separar ambas esferas de realidad y conectarlas más tarde. La conexión inmediata certera es difícil. Muchas acciones sociales están tipificadas y son automatismos sociales (sentido tipificado, "sin sentido" o carente de intencionalidad), como saludar. Otras acciones sociales son plenamente sentido subjetivo (por ejemplo, una declaración de amor). Se podría pensar que la mayoría de las acciones sociales son una mezcla de actuación y sentido subjetivo, correlacionado (es decir, siento, pienso, comunico a otros y actúo en consecuencia), discrepante consciente (como el engaño, comunicar un sentido subjetivo y actuar en forma discrepante) o discrepante inconsciente (patologías de personalidad ${ }^{4}$ ). Todas las combinaciones son posibles.

La antropología y las sociologías hermenéuticas tienen la ilusión de que pueden descubrir el sentido subjetivo a través del análisis del discurso o la representación. Sin embargo, afirmamos que el plus de estas metodologías, en comparación con la idea que "es lo que se dice", es un triunfo pírrico. La única salvedad la constituye el uso de estas técnicas en situaciones de patologías, pero, en verdad, si un hablante quiere engañar a un "codificador" o "investigador comprensivo", lo hará. La única justificación para el uso de técnicas cualitativas es exactamente la misma de las técnicas cuantitativas: conocer a los agregados sociales, usando el individualismo metodológico a través de las encuestas o entrevistas en profundidad o mediante otras técnicas. La exactitud y completitud o profundidad de los hallazgos con metodologías cualitativas y cuantitativas poseen la misma validez y son complementarios. En ambos casos, los agentes pueden engañar al codificador, si se lo proponen.

Metodológicamente, rescatar el carácter nomotético e ideográfico de casi todas las disciplinas, implica — también - rescatar lo provechoso de la inferencia válida como la incoada. En efecto, en la argumentación científica encontramos estructuras legales o válidas (inferenciales deductivas) y cuasi-tendenciales o ló-

Principia, 12(1) (2008), pp. 1-33. 
gicamente no válidas (inferenciales inductivas). Pero la validez de una inferencia lógicamente no válida, nada indica respecto de la fecundidad de un enunciado. Como lo expresa Bunge "el llegar a una clase de conclusiones verdaderas no es un criterio de validez, así tampoco la validez o corrección formal no garantiza la fecundidad de una argumentación: la validez y la fecundidad son propiedades independientes una de otra. El ideal, desde luego, es combinar la fecundidad con el rigor, pero esto debe ser más una aspiración que una exigencia puesta desde el comienzo, pues ninguna línea de pensamiento podría acaso arrancar si se le impusieran severos criterios de rigor." (Bunge 1983, p. 860).

Ahora bien, la típica objeción de los cualitativos y hermenéutas es que el acceso al significado no es posible bajo procedimiento nomológico. Sin embargo, las mismas definiciones de sus objetos lo contraindican.

(la cultura) denota un patrón históricamente transmitido de significados incorporados en símbolos, un sistema de concepciones heredadas expresadas en formas simbólicas por medio de los cuales los hombres comunican , perpetúan y desarrollan su conocimiento para y actitudes hacia la vida. (Geertz 1973, p. 89)

¿Acaso no es plausible nomologizar un patrón? La confusión lamentable de los etnometodólogos radicales consiste en pensar que un significado es algo esencialmente diferente a una conducta. Obviamente, lo más racional es postular que ambos son igualmente objetivos, existen y generan consecuencias observables en los grupos humanos. Como piensan los antropólogos, los hombres son seres suspendidos en redes de significado que el mismo ha tejido y, por lo tanto, el objetivo de las ciencias socioculturales es la correcta interpretación de esos significados. Pero el error es pensar que en términos metodológicos distinguir "significado" de "hecho" constituye novedad o la inauguración de una epistemología antinomológica. La relación entre significante y significado no es más que la regla que conecta la expresión lingüística con un referente empírico o un conjunto de reglas sobre construcción de enunciados (lenguaje) cuya máxima expresión es la lógica.

Incluso Popper plantea "un problema puramente teorético —un problema de ciencia pura - radica siempre en encontrar una explicación, la explicación de un hecho, de un fenómeno, de una regularidad notable o de una excepción igualmente notable" (Popper 1973, p. 114). Es decir, aboga por una concepción de explicación Hempeliana, donde lo idiosincrático o particularista se postula como excepción a la ley: este sería el caso de los grandes hitos históricos.

Así, la explicación social posee todas las características que habitualmente se Principia, 12(1) (2008), pp. 1-33. 
atribuyen a la explicación nomológica, además de algunas características adicionales que afectan su forma lógica o estructura, que se derivan de su objeto de estudio. Las características en común son las que permitirían afirmar que la sociología forma parte de las disciplinas científicas (lo que a su vez nos hace defender la hipótesis ontológica de que la realidad es una sola y la tesis metodológica de la unidad de la ciencia), pero de una manera particular (de que esta única realidad está estructurada en niveles cuyo funcionamiento o dinámica puede ser original, pero complementaria: lo social es un nivel que comparte características con los otros niveles, pero que se diferencia de éstos por tener características propias que le imprimen una fisonomía particular y un modo de ser propio). Esta óptica, permite la exploración fructífera de los aportes de la escuela ideográfica o de las "geisteswissensschaften", así como también aquellos aciertos de la escuela nomológica o de las "naturwissenschaften".

El problema es la tesis de la simetría del modelo nomológico deductivo: si no hay predicción, no hay explicación; y viceversa. En consecuencia, si no podemos predecir, es porque no podemos explicar y si no podemos explicar, eso quizás signifique que no tenemos teoría social alguna, pues, como plantea Fallding, "tener una teoría sobre algo es tener una explicación para ello" (Fallding 1968, p. 501).

Pero existen muchos modelos explicativos que predicen, como los electorales, aunque de un modo débil (como tendencia), pues el término modelo en la literatura sociológica no tiene un sentido matemático: "sólo es un sistema de conceptos que es útil para mapear variables en un área de estudio determinada" (Fallding 1968, p. 510). Además, en el nivel operativo, empiezan a manifestarse las dificultades, pues descubrimos que las variables no siempre pertenecen a una misma dimensión y surge, entonces, el problema de cómo se vinculan las dimensiones o los subconjuntos. Este tema ha sido abordado con insistencia en la teoría sociológica contemporánea (Alexander 1992). Las consecuencias de esta consideración son, básicamente, dos: 1. Las ciencias sociales deben trabajar interconectadamente, ya sea bajo la denominación de multidisciplinariedad, transdisciplinariedad o interdisciplinariedad (Bunge 2004, p. 342-3), y 2. Las explicaciones en ciencias sociales deben tener una forma inter-nivel no-reductivas (Bunge 1999a, 1999b). Esto último, entre otras ventajas, podría significar superar en la práctica de manera más o menos definitiva el problema del vínculo micro-macro y la conexión individuo-sociedad.

Desde una perspectiva disciplinaria, por ejemplo economía, puede verse cómo se aborda el problema de los niveles y su articulación. Solow, afirma: "Pienso que la economía debiera, en este sentido, ser una disciplina "localizada". Debiera estudiar mecanismos específicos que detecte, subyacentes en los fenómenos eco-

Principia, 12(1) (2008), pp. 1-33. 
nómicos, cadenas de causa y efecto inmediato que pudieran existir en algunas industrias y en algunos países, y quizás no en otros. Debiera tratar de comprender como funcionan estos mecanismos y cuáles son los parámetros determinantes, de qué forma dichos parámetros se conectan con la realidad, como diseñar y calibrar un modelo de cada mecanismo específico (Solow 1993, p. 56). Su programa "epistemológico" podría definirse así "... si el enfoque (mecanísmico) se hace desde un nivel intermedio, habrá siempre que encarar interrogantes muy concretas. ¿De qué manera este mecanismo específico influye sobre la conducta del siguiente sistema de mayor nivel, o cómo puede este mecanismo específico o patrón conductual ser explicado en términos del siguiente nivel más bajo?" (Solow 1993, p. 59). Lo mismo ha planteado Bunge (2004, p. 41).

\section{Desarrollos y dificultades del modelo nomológico en ciencias sociales}

No hay un veredicto claro respecto del modelo nomológico. Pero Stinchcombe (1970) como grandes sociólogos del siglo XX (Durkheim, Merton, Lazarsfeld, Boudon, etc.) se rigieron por el modelo nomológico-deductivo, donde el objetivo a la vista fue dilucidar estructuras causales complejas, sin importar si las explicaciones adoptaran fisonomías demográficas, funcionales o historicistas. También se ha intentado reducir la perspectiva comprensiva a la nomológica. Popper defiende, desde la lógica de los problemas, la siguiente idea: "La investigación lógica de los métodos de la economía política lleva a un resultado aplicable a todas las ciencias de la sociedad. Este resultado evidencia que hay un método puramente objetivo en las ciencias sociales al que cabe muy bien calificar de método objetivamente comprensivo o de lógica de la situación. Semejante ciencia social objetivamente comprensiva puede ser desarrollada independientemente de todas las ideas subjetivas o psicológicas. Consiste en analizar la situación de los hombres que actúan lo suficiente como para explicar su conducta a partir de la situación misma, sin más ayudas psicológicas. La "comprensión" objetiva radica en nuestra conciencia de que la conducta era objetivamente adecuada a la situación" (Popper 1973, p. 117).

Esta lógica de la situación es bastante similar con el planteamiento de Weber respecto de los tipos ideales, los que según Bunge, son un dispositivo metodológico que tiende un puente entre lo nomotético y lo ideográfico (1999a, p. 37).

En su texto clásico "Metodología de las ciencias sociales", en el acápite sobre tipos ideales y la construcción de teoría, Weber se pregunta "¿Cuál es el significa-

Principia, 12(1) (2008), pp. 1-33. 
do de tales construcciones típico ideales para una ciencia empírica? ... Se trata aquí de construir relaciones que nuestra imaginación acepta como plausiblemente motivadas y por lo tanto como "objetivamente" posibles" y que se presentan como adecuadas desde el punto de vista nomológico" (Gutiérrez \& Núñez 1971, p. 221). Pero, en el mismo texto, se objeta después: "la meta de la construcción de conceptos típico ideales es siempre hacer más claramente explícito no la clase o el carácter promedio sino más bien el carácter singularmente individual de los fenómenos culturales". Pero el tipo ideal siempre, en cualquier caso, fue concebido como medio para Weber y no como un fin de la investigación sociológica, como se suele suponer.

Sin embargo, detractores y defensores del modelo nomológico de explicación han insistido en los problemas de la explicación en ciencia social. Un recuento arbitrario podría considerar los siguientes problemas:

1. El uso de idealizaciones en ciencias sociales, de acuerdo al modelo de Hempel, adolece de una teoría general en tales disciplinas, cuyas idealizaciones no están subsumidas bajo leyes más generales o teorías más amplias, con evidencia confirmadora independiente (Rudner 1987, p. 99)

2. La confusión en la noción de leyes generales, por parte de los defensores del modelo de Hempel, que desconoce para el caso de las ciencias sociales una doble distinción entre tipos de leyes generales: primero, entre leyes generales de tipo universal y leyes de probabilidad; segundo, entre leyes generales no restringidas y leyes generales restringidas o cerradas" (Gibson 1968, p. 33). Da como ejemplo de ley universal "siempre que se da $A$ se da $B$ (en todo grupo social el poder siempre se concentra en pocas manos)". Al lado de estas leyes, están las que se refieren a características contingentes: $B$ aparece cuando aparece $A$. Estas leyes son las de probabilidad o generalizaciones estadísticas. Respecto a las leyes generales no restringidas y cerradas (restringidas), plantea "se ha dicho ... que las leyes de la economía clásica han de considerarse como leyes generales restringidas que valen solamente para la época en que predominaba el libre cambio. Pero lo único que se puede demostrar es que se aplican a dicho período. Esto es perfectamente compatible con su carácter de postulados no restringidos, referentes a lo que ocurre siempre que se den las condiciones del libre cambio" (Gibson 1968, p. 41).

3. La multicausalidad en física y en ciencias sociales es diferente, pues el principio de la composición de fuerzas opera de manera distinta, debido al influjo de las creencias. Muchas causas que podrían tener consecuencias positivas por separado, pueden tener consecuencias nefastas actuando al unísono. Gibson nos divierte con el siguiente ejemplo "Puede ocurrir, por ejemplo, que cuando el aumento del precio de la cerveza se combine con el convencimiento de que es per-

Principia, 12(1) (2008), pp. 1-33. 
judicial para la salud, su consumo aumente, por estimar el público que es preciso ahogar en cerveza la tristeza provocada por la acumulación de esas dos desgracias" (Gibson 1968, p. 213). Además, "las creencias ofrecen la peculiaridad de que la evidencia que las apoya puede también formar parte de su causa" (Gibson 1968, p. 108).

4. La incomprensión de los sistemas teleológicos, ya sea como dotados de un determinismo funcional o como puramente adscriptos a motivos.

Respecto del primer caso, se encubre que los sistemas funcionales son tipos o subtipos de los sistemas teleológicos. El esquema de Rudner es que una propiedad $R$ característica de algún elemento $W$, ha de ser construida como condición suficiente para la aparición de un estado $N$, estado $N$ que es, a su vez, una condición necesaria para la aparición de algún estado G de finalidad (Rudner 1987, p. 161). Pero ello requiere la especificación del subconjunto $N$ de todos los estados del sistema así como también especificar el subconjunto $G$ de todos los estados del mismo sistema. O sea, la idea de que un sistema teleológico puede tener más de una finalidad y más de un patrón de adaptación para llevarla a cabo. En principio, existe la explicación funcional, pero es muy difícil precisar que estado $N$ o G posee un sistema. Además, como afirma Gaeta "no resulta claro en que sentido cabe hablar de finalidades sino es en relación con seres capaces de tener, de un modo u otro, propósitos" (Gaeta 1996, p. 46).

Respecto del segundo caso, Gibson afirma que "Cuando explicamos la ignición de una cerilla podemos decir que siempre que cualquier caja de cerillas es raspada por una cerilla, ésta se enciende. Pero también podemos decir: siempre que esta caja de cerillas es raspada por una cerilla, la cerilla enciende ... Los motivos humanos se parecen a las cajas de cerillas en que todos tienen una historia, y por ello permiten ambos tipos de explicación" (1968, p. 54). Es decir, así como la caja de cerillas es un objeto material duradero, un motivo es un estado duradero de la mente. "Cuando la mente recibe el rasponazo de una circunstancia apropiada, se enciende en una intención o en una acción" (Gibson 1968, p. 52).

Además, la explicación de sistemas teleológicos no sólo debería tener en cuenta los propósitos, sino también la creencia en la aptitud de nuestras acciones para alcanzar un fin, lo que es síntoma de racionalidad o irracionalidad dependiendo de cuánta evidencia posea el sujeto respecto de la efectividad de dichos medios.

5. El tratamiento de la racionalidad en las explicaciones sociales, ya que supone (i) un conjunto extenso de supuestos improbables y, (ii) en ocasiones confunde racionalidad con idiosincrasia. Sobre lo primero, los ataques han estado concentrados en los supuestos de la teoría de la acción racional, especialmente

Principia, 12(1) (2008), pp. 1-33. 
el supuesto de disponibilidad de información (Bunge 1999a, Hollis, 1998). Sobre lo segundo, se ha planteado que los teóricos han sobreestimado la irracionalidad de las acciones humanas, desechando el hecho que "aparece con regularidad en el curso ordinario de la vida. Si preguntamos porqué el mecánico de un garaje ajusta un tornillo determinado y no otro, la respuesta nos dirá que, evidentemente, lo hace porque ha observado primero qué es lo que no funciona en el coche. Para explicar su acción, no necesitamos conocer su psicología, sino más bien el funcionamiento de los motores"(Gibson 1968, p. 68).

6. La estructura explicativa de las ciencias sociales, dado que el modelo nomológico no distingue entre naturaleza y sociedad (o humanidad).

De todos los problemas anteriores, creemos que la dificultad mayor para dar cuenta de nuestro principio socioantrópico es el de la estructura. Dedicaremos el resto del trabajo a este problema.

\section{Dos propuestas de modificación de la estructura explicativa en ciencias sociales}

Bunge nos brinda un ejemplo de explicación sobre el origen del Estado de Bienestar.

Plantea el autor: "¿Porqué fue instituido el Estado de Bienestar?

Posible explicación:

Generalización: La pobreza es fuente tanto de infelicidad personal como de agitación social.

Dato: Hay gente pobre en nuestra sociedad.

Juicio de valor: La pobreza es indeseable, por ser dolorosa y denigrante para los pobres y peligrosa para los ricos.

Norma: Para prevenir las consecuencias de la agitación social, se instituye un estándar básico de vida mediante la redistribución de la riqueza social pagando impuestos para los programas sociales" (Bunge 1999b, p. 52).

Así, su modelo explicativo es:

Teoría o hipótesis sobre mecanismos testeables + Circunstancias $=$ Explanandum

Para el caso de las ciencias sociales, esta estructura lógica, de una verdadera explicación científica, posee el mismo esquema básico de Hempel. Es complementaria, con la diferencia que en el conjunto de explanans se deben añadir los

Principia, 12(1) (2008), pp. 1-33. 
juicios de valor y las normas. Bunge menciona el caso de la teoría de Merton sobre la anomia, indicando que él explicó la anomia o falta de normas como efecto de la desigualdad entre la norma social (o aspiración) y oportunidad: una discrepancia entre lo que es socialmente deseable y aceptable y lo que el individuo puede obtener realmente a través de medios aceptados socialmente. Esta disociación entre norma y hecho puede ser el mecanismo de la conducta desviada (Bunge 1999b, p. 51).

Aún así, creemos que esta estructura esconde lo fundamental, cual es que los juicios de valor siempre existen pero no siempre operan. Habría que buscar el factor catalizador de los juicios de valor que son elementos constituyentes de la explicación sobre el nacimiento del Estado de Bienestar y, francamente, dudo que ésta sea del dominio ético. Como defiende el autor, una teoría sociológica trata de hechos y, a mi entender, los hechos son los siguientes: (i) el auge económico de la primera mitad del siglo XX generó una creciente desigualdad social en los países occidentales, y, (ii) el modelo de planificación centralizado permitió a la URSS un desarrollo económico y social, el socialismo ganó adeptos vía demostración. A ello podemos agregar la ley de que "las élites en el poder tienen por principal objetivo o finalidad mantenerse o acrecentar su poder". De tal forma que, como una forma de mantenerse en el poder, en el contexto del éxito del efecto de demostración del modelo socialista, los países occidentales generan mecanismos para disminuir o mitigar los efectos de desigualdad social que genera el capitalismo, inventando el Estado de Bienestar.

Ahora bien, globalmente, su posición no es algo que difiera mucho del individualismo metodológico clásico que adoptan las ciencias sociales. Como afirma Raymond Boudon en el prólogo (Bunge 1999b), esa postura es sólo otro nombre para el "individualismo metodológico contextual (del mismo Boudon) o el "individualismo metodológico" de Weber.

De hecho, los elementos del sistemismo de Bunge siguen siendo los individuos, no las dobles contingencias de las expectativas. Desde nuestra visión, los elementos de los sistemas sociales básicos son las dobles contingencias de las expectativas individuales, que no es la suma o necesariamente la reciprocidad de las expectativas individuales. Las dobles contingencias son estados (como forma) con contenido (intencionalidad), por ejemplo la forma "confrontación" con el contenido "por cuotas de poder". Tal doble contingencia, cuando se comunica, puede dar pie a un sistema social superior, por ejemplo, un grupo, donde un tercero añadido (otro individuo), hará emerger una propiedad social nueva, que es el poder bajo la forma de una alianza entre dos individuos con expectativas recíprocas en función de un objetivo de futuro en detrimento de las expectativas

Principia, 12(1) (2008), pp. 1-33. 
del individuo que queda aislado. Una alianza no tiene sentido sin la existencia de un tercero y es este tercero el que explica la asimetría de poder y, finalmente, la emergencia de un líder y los seguidores o subordinados. Es decir, el tercero no es un mero elemento del medio de s, que de acuerdo a Bunge participaría de la estructura del sistema. Tal planteamiento impide explicar la emergencia de los sistemas sociales superiores y finalmente se obtiene una visión de la sociedad como conjunto de multiplicidad de parejas y tribus. Por el contrario, focalizando a las dobles contingencias como los elementos básicos, obtenemos una visión que permite identificar el paso o la transición desde un sistema interactivo a uno grupal. Estas transiciones, a su vez, permiten sustentar un modelo de estructura social de varios niveles.

Estamos de acuerdo con Bunge en que la explicación de cobertura legal adolece de considerar la subjetividad humana o social. En este trabajo defendemos la siguiente tesis: la explicación sociológica adolece de un tratamiento del libre albedrío. El porqué reemplazamos subjetividad por libre albedrío, es debido a que la subjetividad es intersubjetividad, y ella se funda en expectativas. Luego la subjetividad es pauta regular y puede ser tratada como tendencia o ley social. Además, las subjetividades, sociológicamente consideradas, siempre varían de sociedad a sociedad. Forman parte, entonces, de la circunstancia. Pero lo verdaderamente importante es la libertad, que en principio siempre es personal o individual. Esto nos lleva a considerar que toda acción social es decisión, elección, etc. y ella, a la vez, debe considerarse en la secuencia siguiente de acciones sociales en un dominio dado.

Podemos complementar lo ya dicho sobre las expectativas, con el concepto utilizado por Brief y Aldag (1981), quienes desde una visión psicosocial, lo han dilucidado de manera suficiente. Centrando su interés en las fuentes cognitivas (psicológicas) de la motivación, se podría decir que los autores definen las expectativas sociales como un complejo compuesto por: expectativas de resultado y expectativas de autoeficacia. Las expectativas de resultado sería el pronóstico que el individuo realiza respecto a cierto curso de acontecimientos probables y las expectativas de autoeficacia serían las expectativas de su propio desempeño en ese curso de acontecimientos. Así, cada interacción sería una combinación de $2 \times 2=4$ expectativas de desempeño de ego $(A$ y $B)+$ expectativas de desempeño de alter $(A$ y $B)$. Todas ellas se estabilizarían socialmente bajo un estado (forma) con cierto contenido (intencional). Ese estado podría ser el objeto de la observación social, el que tendría que ingeniar procedimientos para su descripción, pero que, necesariamente, no es reducible a la sumatoria de ningún conjunto de pruebas psicométricas aplicadas a los participantes.

Principia, 12(1) (2008), pp. 1-33. 
No existen expectativas "sociales" de manera llana, sino que, más bien, las expectativas pertenecen y se generan entre los agentes o, si se prefiere, entre grupos con intereses diversos. La colaboración o la indiferencia es un juego mutuo de palabras y actos de unos respecto a otros. Las expectativas generales de los agentes son creadas de acuerdo a cómo cada cual "proyecta" lo que hará el otro y él mismo.

La estructura lógica de la explicación, además, requiere una reflexión más filosófica en torno al término "circunstancia": "circunstancia es todo aquello que está en torno mío; es decir, todo lo que encuentro o puedo encontrar a mi alrededor ... Con esto queda dicho que no cabe, en términos rigurosos, ninguna descripción de mi "circunstancia", porque sería literalmente infinita" (Marías 1956, p. 43). Por el contrario, "el término situación alude, en cambio, a una realidad mucho más restringida; sólo mienta aquellos elementos de la circunstancia cuya variación define cada fase de la historia, que nos sitúan en un nivel histórico determinado" (Marías 1956, p. 44). Su referencia a la situación podría tener alguna analogía de interés con un concepto de "estado", a propósito del teorema de la doble contingencia.

La explicación científica social es de hechos y leyes. En ambos casos, el papel de las expectativas es fundamental, puesto que las leyes sociales son expectativas estabilizadas históricamente y los hechos, la mayoría de las veces, dependen de las situaciones de "estado" en las dobles, triples o cuádruples contingencias de expectativas entre actores y organizaciones. Lo interesante del fenómeno de "lo social" es que, a diferencia de los seres vivos en general, el desarrollo sociocultural y como especie depende de expectativas que se construyen socialmente. No hay un programa preestablecido para la evolución humana. La tesis uniría la determinación legal y un cierto tipo de nuevo "explanans", como expectativa lanzada hacia el futuro.

Si es así, la predicción incorpora un elemento de voluntad. No sería posible predecir, pues la conducta social no es regular siempre y puede cambiar voluntarísticamente. Igual fenómeno se observa en las organizaciones. Pero desde cierta perspectiva, siempre es regular la conducta social (intersubjetiva y fundada en la reciprocidad de perspectivas), pues remite a tipificaciones, pero producto de los azares (rol de la singular-novedoso en el universo social), que alteran el procesamiento de las expectativas típicas, las acciones sociales mutan a través del tiempo. La novedad siempre emerge como propiedad en un sistema producto del determinismo del sistema inferior o superior. La elección de una regla novedosa particular está determinada por la información que el agente tiene a su disposición en un momento dado, información que siempre es parcial. Es decir, no hay

Principia, 12(1) (2008), pp. 1-33. 
ningún agente del sistema capaz de observar todo lo que los otros agentes están haciendo; y, por lo tanto, eligen una regla de conducta sobre la base de esta información parcial. Los sistemas sociales son dinámicos y adaptativos.

La propuesta es que la estructura lógica explicativa de las ciencias sociales debe completarse introduciendo, además de las leyes sociales y las condiciones concomitantes, las expectativas de los agentes. Las ciencias sociales no pueden seguir siendo sólo sociales (económicas o políticas), sino crecientemente ocupadas del nivel psicológico social, especialmente del fenómeno de los organizadores e innovadores, es decir del cómo los líderes y sus seguidores producen efectos hacia arriba de la estructura de múltiples niveles de la realidad social.

Como hipótesis para futuras investigaciones, proponemos la siguiente estructura lógica para explicar en ciencias sociales:

Ley o mecanismo (nivel social) + circunstancia (nivel $k$ ) + Teorema de la doble contingencia de las expectativas (nivel psicosocial) $=$ explanandum.

Así, en base al mismo ejemplo, la explicación alternativa a la postulada por Bunge es:

Generalización: Las élites harán lo que sea para mantenerse en el poder, especialmente propaganda de juicios de valor y acciones que evidencien su compromiso con éstos, con el fin de tener credibilidad entre la población y seguir en el poder.

Dato1: Existe la desigualdad social bajo el capitalismo.

Dato2: Existe la "promesa" socialista.

Expectativa: La expectativa de la élite es que si desde el poder político les damos tanta igualdad social como la que promete el socialismo, el efecto demostración frenará el avance del ideario socialista y lograremos mayor integración social. Mientras que la expectativa de las masas será que si el sistema otorga ciertas prebendas similares a las del socialismo, no habrá necesidad de hacer la revolución. Lo relevante es que para que una expectativa funcione debe enlazarse una con la otra, y esto rige para las expectativas de la élite como para las expectativas de las masas: es el teorema de la doble contingencia.

Explicandum: Hágase el Estado de Bienestar, para contrarrestar la desigualdad social del desarrollo capitalista y contener el avance del comunismo.

Pero aunque las expectativas son el material concreto de la libertad humana, la disposición de éstas en la arena social influye fuertemente, ya que la comuni-

Principia, 12(1) (2008), pp. 1-33. 
cación de tales expectativas por parte de los agentes condiciona la evolución de las expectativas mismas y, por tanto, la evolución de los acontecimientos.

Los problemas predictivos de las ciencias sociales son insolubles en virtud de que las expectativas son cambiantes, pero principalmente, porque es usual que estén ocultas.

Ello arroja variabilidad a cualquier esquema explicativo o predictivo. El Cuadro $\mathrm{N}^{\circ} 1$ refleja lo anterior:

CUADRO $\mathrm{N}^{\circ}$ 1: Estructura tradicional de la explicación y rasgo de los enunciados

\begin{tabular}{|l|l|}
\hline Estructura tradicional en ciencias sociales & Rasgo de los enunciados \\
\hline Mecanismo o legalidad (Explanans) & Estabilidad \\
\hline Circunstancia (Explanans) & Estabilidad \\
\hline Resultado (Explanandum) & Variabilidad ó estabilidad \\
\hline
\end{tabular}

Pero: ¿Cómo es posible que "Estabilidad" + "Estabilidad" = "Variabilidad", como alternativa? Lo más lógico es pensar que hay un elemento oculto en esta estructura, un elemento que le da variabilidad al explanandum. Ese elemento es la doble contingencia de expectativas. Según nuestra hipótesis, tenemos en el Cuadro $\mathrm{N}^{\circ} 2$ que:

CUADRO $\mathrm{N}^{\circ} 2$ : Estructura propuesta de la explicación y rasgo de los enunciados

\begin{tabular}{|l|l|}
\hline Estructura propuesta para las ciencias sociales & Rasgo de los enunciados \\
\hline Mecanismo o legalidad (Explanans) & Estabilidad \\
\hline Circunstancia (Explanans) & Estabilidad \\
\hline Doble contingencia de expectativas (Explanans) & Variabilidad ó estabilidad \\
\hline Resultado (Explanandum) & Variabilidad ó estabilidad \\
\hline
\end{tabular}

Es decir: "Estabilidad" + "Estabilidad" + "Inestabilidad" = "Variabilidad ó estabilidad".

Ahora bien, en el caso de que las predicciones resulten, quiere decir que, como fundamentaban Parsons y Shils, "existen expectativas recíprocas" (1951, p. 3-29) y por lo tanto el sistema de acción es suficientemente estable como para predecirlo. Las expectativas son transparentes y han sedimentado en hábito.

Bunge seguramente replicaría que el juego de expectativas es un mecanismo. Y es verdad. Pero la razón para distinguirlo es que "allí se juega la libertad", es caprichoso y por tanto no susceptible de ser tratado bajo la hipótesis determinista. Para decirlo en sus términos, es el puente entre la ciencia social y la sociotecnología, entre la descripción y la intervención del mundo. Es la verdadera (y quizás

Principia, 12(1) (2008), pp. 1-33. 
única) razón porqué las predicciones en ciencias sociales aciertan con poca frecuencia.

\section{Conclusión}

La teoría social debería apuntar a la reflexión, plausibilización y perfeccionamiento de aquellos modelos que predicen o describen con riqueza una cantidad suficientemente amplia de hechos interconectados. Eso es todo. Su relevancia debería estar garantizada por una mejor comprensión y conocimiento de la realidad social, pero también por su utilidad social y política. Luego, las teorías de este tipo se construyen en base a focalizaciones, no a base de distinciones lógicas o hipótesis ad-hoc (a menos que sean distinciones reales e hipótesis enlazadas sistemáticamente con el cuerpo de conocimiento previo). Así, la única posibilidad es retomar el camino de las teorías específicas: teoría del contrato, teoría del puesto, teoría del crimen, etc. La ciencia social requiere aplicaciones específicas.

Nuestra propuesta sugiere algunas respuestas.

Una teoría es un sistema de enunciados vinculantes que postula algún mecanismo en distintos niveles de organización: es una teoría mecanísmica multinivel. Tales teorías explican mecanismos de diverso tipo: causales, probabilísticos o mixtos. Siempre los mecanismos deben ser conjeturados a partir de la información empírica y consistentemente con ella.

El supuesto es que el modelo nomológico es el más fructífero, que las ciencias sociales son distintas a las ciencias naturales, y que el modelo nomológico debe complementarse o completarse de la forma propuesta. No se justifica abandonar la pretensión explicativa de las ciencias sociales sólo porque la mayoría de ellas sean incompletas, imprecisas e incluso erróneas. Al contrario, habría que insistir y pensar cómo lograrlas. Las leyes teóricas de todas las ciencias están sostenidas en ciertos supuestos y varios ceteris paribus. Uno de los problemas de las ciencias sociales, salvo la economía, es que no los hemos explicitado.

Finalmente, rescatar el papel de la causación en ciencias sociales es prioritario. Habría que afirmar, simplemente, que nada se genera de la nada y que, obviamente, existe un nexo generativo entre acciones y entre comunicaciones sociales, además de entre acciones y comunicaciones y viceversa. En esa perspectiva, la distinción determinación teleológica vs. determinación causal o la distinción materia-significado son, ambas, falsas: Toda producción implica una intención de producir y finalidad implica una intención de logro. El sentido es transversal a toda acción social, pero ello no significa demarcar falsamente a las ciencias so-

Principia, 12(1) (2008), pp. 1-33. 
ciales de las naturales o resolver de modo idealista falsas antinomias. Finalmente, en tanto esa generación o producción contenga innovación o creación respecto de un estado anterior, podemos hablar de libertad o libre albedrío.

\section{Bibliografía}

Alexander, J. 1992. Las teorías sociológicas después de la segunda guerra mundial. Análisis multidimensional. Barcelona: Gedisa.

Arnhart, L. 2005. Darwinian conservatism. Charlottesville, VA: Imprint Academic.

Brief, A. \& Aldag, R. 1981. The self in organizations. A conceptual revision. Academy of management review 6(1): 75-88.

Bunge, M. 1983. La investigación científica. Madrid: Ariel.

—. 1993. Sociología de la ciencia. Buenos Aires: Siglo XX.

—. 1997. Epistemología. México: Siglo XXI.

—. 1999a. Las ciencias sociales en discusión. Buenos Aires: Sudamericana.

—. 1999b. The sociology-philosophy connection. New Brunswick, NY: Transactions publishers.

—. 2004. Emergencia y convergencia. Novedad cualitativa y unidad del conocimiento. Barcelona: Gedisa.

Dutra, L. H. 2003. Introdução à teoria da ciência. Florianópolis: Editora da UFSC.

Fallding, H. 1968. Explanation theory, analytical theory, and ideal type. In Thompson, K. \& Tunstall, J. (eds) Sociological perspectives. London: Penguin Books.

Gaeta, R. 1996. Modelos de explicación científica. Buenos Aires: Eudeba.

Gibson, Q. 1968. La lógica de la investigación social. Madrid: Tecnos.

Gibert, J. 2006. La conexión libertad-determinismo. Una reconstrucción de la filosofía de las ciencias sociales. Santiago de Chile: RIL.

Geertz, C. 1973. The interpretations of culture. NY: Basic Books.

Gutiérrez, C. \& Núñez, A. 1971. Teoría del método en las ciencias sociales. San José, CR: Educa.

Hempel, C. 1988. La Explicación Científica. Barcelona: Editorial Paidós.

Hollis, M. 1998. Filosofía de las ciencias sociales. Barcelona, Ariel.

Knorr-Cetina, K. 1983. The ethnographic study of scientific work: towards a constructivist interpretation of science. In Mulkay, M. \& Knorr-Cetina, K. (eds.) Science observed. London: Sage, p. 115-39.

Latour, B. 1983. Give a laboratory and I will raise the world. In Mulkay, M. \& Knorr-Cetina, K. (eds) Science observed. London: Sage, p. 141-70.

Little, D. 1998. Microfoundations, method and causation. On the philosophy of social sciences. New Brunswick, NY: Transaction publishers.

Marías, J. 1956. Introducción a la filosofía. Madrid: Revista de occidente.

Marx, K. [1851-2] 1971. El 18 brumario de Luis Bonaparte. Barcelona: Ariel.

Principia, 12(1) (2008), pp. 1-33. 
Michels, R. 1962. Political parties: a sociological study of the oligarchical tendencies of modern democracy. NY: Collier.

Nagel, Th. 2000. La última palabra. Barcelona: Gedisa.

O'Dea, Th. 1966. The sociology of religion. NY: Englewood Cliffs.

Pareto, V. 1945. Manual de economía política. Buenos Aires: Editorial atalaya.

Parkinson, C. N. 1957. Parkinson's law and other studies in administration. Boston: C. Houghton Mifflin.

Parsons, T. \& Shils, E. 1951. Towards a general theory of action. Massachusetts: Cambridge Press.

Pinker, S. 1999. The blank slate, the noble savage, and the ghost in the machine. The Tanner Lectures on Human Values. Yale University; April 20 and 21.

Popper, K. 1973. La lógica de las ciencias sociales. En Adorno, Th. \& Habermas, J. La disputa del positivismo en la sociología alemana. Barcelona: Grijalbo.

Rudner, R. 1987. Filosofía de las ciencias sociales. Madrid: Alianza editorial.

Schütz, A. \& Luckmann, Th. 1973. Las estructuras del mundo de la vida. Buenos Aires: Amorrortu.

Sokal, A. \& Bricmont, J. 1998. Fashionable nonsense. Postmodern intellectual's abuse of science. NY: Picador.

Solow, R. 1993. Crecimiento y equidad. Santiago de Chile: Editorial universitaria.

Stinchcombe, A. 1970. La construcción de teorías sociales. Buenos Aires: Nueva visión.

Thomas, W. I. 1928. The child in America: Behavior problems and programs. NY: Knopf.

Topolski, J. 1985. Metodología de la historia. Madrid: Cátedra.

Turner, J. 1991. Teorizar analítico. En Giddens, A. \& Turner, J. La teoría social hoy. México: Alianza editorial.

Wallace, W. 1980. La lógica de la ciencia en la sociología. Madrid: Alianza editorial.

\title{
Keywords
}

Free-will, determinism, explanation, social sciences.

\author{
Jorge Gibert Galassi \\ Universidad de Viña del Mar \\ Av. Agua Santa 7255, Rodelillo \\ Viña del Mar - Chile \\ Jgibert@uvm.cl
}

\section{Resumo}

O propósito deste trabalho é postular um princípio, que chamarei de "socioantrópico", que permita conectar no mundo social de uma maneira adequada

Principia, 12(1) (2008), pp. 1-33. 
dois termos historicamente antitéticos: livre-arbitrio e determinismo. A principal conseqüência a fazer isto consiste em estabelecer um novo tipo de estrutura explicativa acorde às características especiais da natureza do mundo social. Para fazê-lo, reconstruirei a estrutura convencional da explicação nomológica dedutiva mostrando aqueles aspectos que não são úteis em ciências sociais e posteriormente, formularei uma proposta que resolve teoréticamente o problema das explicações no mundo social.

\section{Palavras-chave}

Livre-arbítrio, determinismo, explicação, ciências sociais.

\section{Notas}

${ }^{1}$ Están los que dicen que si (Bunge 1983, 1999a y 1999b; Fallding 1968; Turner 1991; Wallace 1980) y los que dicen que no (Knorr-Cetina 1983; Latour 1983).

${ }^{2}$ Indudablemente no pretendemos desarrollar una de las preguntas más relevantes de la filosofía en unas pobres páginas. Para efectos de una discusión más larga desde la óptica del trabajo, véase Gibert (2006).

${ }^{3}$ Sobre lo cual hay consenso desde ópticas muy distintas, tanto en las ciencias neurocognitivas, como recientemente en la filosofía. Ver Arnhart (2005) y Pinker (1999).

${ }^{4}$ Se podría afirmar que desde esta óptica, los trastornos de personalidad son la imposibilidad que tiene un sistema síquico de ejercer su libertad (en términos de pensamientos y emociones) en los sistemas determinísticos de un nivel superior (interacción social y otros más). En otras palabras, no se logra la ecuación correcta para un sistema síquico situado socialmente.

Principia, 12(1) (2008), pp. 1-33. 